\title{
New Lung Imaging Findings in Chronic Respiratory Diseases
}

\author{
Samuel Y. Ash, MD, and George R. Washko, MD \\ Division of Pulmonary and Critical Care Medicine, Department of Medicine, Brigham and Women's Hospital, Boston, MA, USA
}

\section{ABSTRACT}

Rapid advances in image analysis technology have revealed new insights into chronic respiratory disease. In the approximately one hundred years since the first medical use of X-rays, visual, or qualitative, analysis of images acquired using traditional radiography as well as computed tomography and other modalities like magnetic resonance imaging have dramatically altered how we diagnose and care for patients with lung diseases. More recently, utilizing ever increasing computational power, the quantitative analysis of medical imaging, especially computed tomography, has further enhanced our understanding of chronic respiratory diseases. Herein we summarize some of the recent findings in the medical imaging of lung diseases, emphasizing quantitative analysis in particular. (BRN Rev. 2017;3:121-35)

Corresponding author: Samuel Y. Ash, syash@partners.org

Key words: Computer assisted. Image processing. Lung diseases. Multidetector computed tomography. 


\section{INTRODUCTION}

Imaging and image analysis have become an integral aspect of clinical investigation in chronic respiratory diseases. Broadly, image analysis can be described as using either a traditional qualitative approach in which the characteristics of a radiographic image or set of images are described or scored visually, or a quantitative approach that utilizes computational analysis techniques. Advances in image resolution coupled with ever expanding device memory and processing capabilities have transformed quantitative work, in particular from the simple measurement of the density of the lung parenchyma to textural analysis and other analytic techniques that utilize machine learning and other advanced computational tools. This expansion of analytic techniques has enabled more nuanced analysis of lung diseases such as emphysema and fibrosis, and the broad uptake of these and other techniques in the research setting has expanded our focus to diseases not typically thought of as having striking imaging findings, such as asthma. In addition, these advances have enabled image analysis to look beyond the lung parenchyma itself to the nonpulmonary manifestations of lung disease. Herein we provide a concise review of the history of quantitative image processing before examining some select advances in the fields of chronic obstructive pulmonary disease (COPD), pulmonary fibrosis, and asthma. Because much has been written on the qualitative analysis of imaging in respiratory diseases, we will primarily discuss quantitative analysis techniques in chronic lung diseases. In addition, due to its prevalence and the breadth of research on its use we will primarily focus on computed tomography (CT) imaging though other imaging modalities will be discussed where appropriate.

\section{HISTORY}

In a little over a century, medical imaging, and the use of X-ray in particular, has advanced from the revolutionary but crude images obtained using Crookes' tubes to high resolution images obtained using $\mathrm{CT}^{1}$. While the qualitative interpretation of medical images by radiologists and other clinicians has been used since the earliest days of X-rays in routine clinical care as well as in research, quantitative analysis of medical imaging only became a viable source of data for clinical investigation in the $1980 \mathrm{~s}^{2}$. One of the first features of the lung to be explored using quantitative techniques was emphysema seen on CT imaging. Early approaches to measuring emphysema focused on measuring mean lung density with the hypothesis that the excess low attenuation emphysematous tissue would result in measurable decreases in mean density of the entire lung ${ }^{3}$. However, a large amount of emphysema must be present in order to significantly change the mean lung density. An alternative approach, which has become the most frequently used method of quantifying emphysema utilizes a density threshold whereby tissue with a density below a certain threshold is classified as emphysematous and as non-emphysematous if above that threshold (Fig. 1) ${ }^{4}$. There have been several studies to determine the best density threshold to select in order to detect emphysema. Perhaps most notable was a small study from the 1980s by Hayhurst et al. ${ }^{5}$ of 11 patients with centrilobular emphysema 


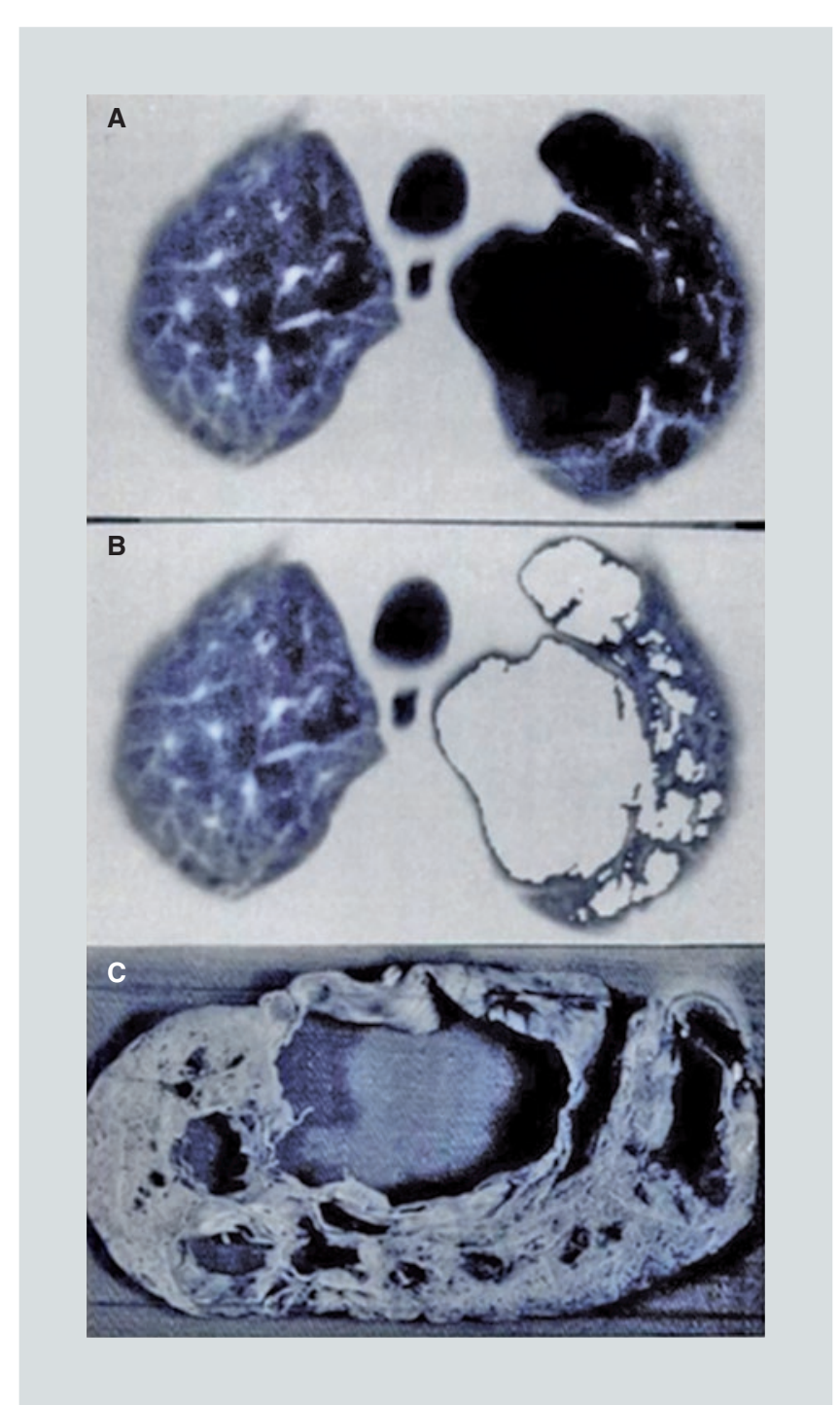

Figure 1. A: Representative image of computed tomography (CT) scan slice from a patient with severe emphysema. B: Density mask applied to the CT image from the top panel highlighting all low attenuation voxels. C: Pathologic specimen corresponding to the above CT images (reproduced with permission from Muller NL et al. ${ }^{4}$ ).

showing that those individuals with emphysema had significantly more voxels, or three dimensional pixels, with densities between $-1,000$ and -900 Hounsfield units (HU) than those with normal lungs. Based on this and other studies the density threshold used most commonly to identify emphysema is $-950 \mathrm{HU}^{4,5}$. This in-vivo binary classification of the lung is a strong predictor of histopathologic measures of airspace dilation and provides an objective assessment of lung destruction that is highly correlated with measures of lung function ${ }^{4,6}$.

Despite these strong correlations though, densitometric CT analysis has thus far found a limited role in the direct clinical care of patients. There are a variety of potential reasons for this slow adoption. One worth particular mention relates to the reproducibility of many of the most basic CT derived lung measures. As with pulmonary function tests, CT measurements are dependent, to some extent, on patient effort and coordination with the testing equipment. This is especially true for CT measured lung volume and density. For instance, CT measured mean lung density changes by a factor of 2.6 from inspiration to expiration ${ }^{7}$. Thus if images are acquired during the wrong portion of the respiratory cycle, or if the patient does not take as deep a breath as during their last scan then non-disease related differences may appear. One potential solution to this problem is spirometric gating of CT acquisition in which images are acquired in a timed way based on a linked spirometer ${ }^{8}$. Unfortunately, this approach is not routinely clinically available. In addition, several small studies have suggested that in many cases it may not be necessary to employ spirometric gating in order to obtain reproducible measurements, and other image analysis techniques such as image co-registration may be able to at least partially overcome some of the issues specifically related to differences in longitudinally acquired scans ${ }^{9-11}$. For now then the majority of quantitative analysis is performed on non-spirometrically gated studies.

One place where quantitative $\mathrm{CT}$ analysis has proven particularly useful is in the identification of patients with emphysema who may benefit 
from lung volume reduction surgery ${ }^{12}$. In the National Emphysema Treatment Trial, a randomized controlled trial of lung volume reduction surgery, while there was no survival benefit to the procedure overall, those patients who had a decreased exercise capacity and upper lobe predominant emphysema did benefit from the procedure. Additional work has demonstrated that densitometric analysis may be the most effective method for identifying patients with the latter feature ${ }^{13-16}$.

\section{NEW APPROACHES}

\section{Chronic obstructive pulmonary disease}

\section{INTRODUCTION}

Over the past decade, much of the work on quantitative image analysis in COPD has focused not only on an ever expanding list of associations with densitometric emphysema, but also on novel approaches to characterize both intra-pulmonary and nonpulmonary manifestations of chronic lung disease. From an intra-pulmonary and $\mathrm{CT}$ specific standpoint, the findings can be broken down by anatomic compartment: parenchyma, airways, and vasculature.

\section{PARENCHYMA}

With regard to the lung parenchyma, it has long been recognized that the secondary pulmonary lobule is a functional subunit of the lung whose radiologic appearance may be diagnostic for the presence of disease and its subtype. Although densitometric analysis is a powerful tool for measuring disease severity, it does not accurately detect the secondary pulmonary lobule and therefore cannot fully describe the anatomic distribution of lung diseases. For example, using densitometry alone, it can be challenging to distinguish between decreased lung density due to gas trapping, as in the case of bronchiolitis, and decreased density due to parenchymal destruction as occurs in emphysema. Multiple different approaches have been used to overcome this problem, many of which use the local radiographic properties of lung parenchyma are used to define a particular tissue subtype. One such approach using a specific method termed local histogram analysis has been shown to be able to identify emphysema subtypes. This type of analysis allows for the analysis of clinical associations with different tissue subtypes of emphysema. For instance, the percentage of mild centrilobular emphysematous lung defined using this method is associated with a lower forced expiratory volume in one second $\left(\mathrm{FEV}_{1}\right)$, more dyspnoea and a shorter six minute walk distance, even in those smokers with preserved lung function suggesting that this radiographic pattern may be a maker of early disease ${ }^{17}$. This and similar automated tools may also be able to help identify patterns of emphysema associated with specific genetic abnormalities and other risk factors.

\section{AIRWAYS}

Qualitative analysis of the airways in COPD has been a part of both clinical research and clinical care for several decades. For instance, prior work has demonstrated that bronchiectasis on CT in those with COPD is associated with a longer recovery from acute exacerbations of COPD (AECOPD) as well as increased mortality ${ }^{18,19}$. The quantitative CT analysis of 
airways in COPD, on the other hand, has yet to find widespread clinical use, but has helped shape our understanding of both disease severity and, perhaps more importantly, disease aetiology. It has been known for some time that patients with COPD, especially those with chronic bronchitis, have airway wall thickening, which is most commonly expressed as an increase in the wall area (WA) percent $(\mathrm{WA} \%=\mathrm{WA} /$ total bronchial cross sectional area $x$ 100) ${ }^{20-22}$. More recently though, additional work has demonstrated that while smokers who have higher $\mathrm{WA} \%$ do have a lower percent predicted $\mathrm{FEV}_{1}$ $\left(\mathrm{FEV}_{1} \%\right)$, they also tend to have a lower airway cross sectional area and a lower total WA. This suggests that those smokers with COPD either have a reduction in airway calibre that is greater than the relative decrease in WA, or that they had smaller airways at baseline, perhaps even prior to their smoking exposure ${ }^{23}$. These findings are particularly interesting in light of the recent longitudinal work by Lange et al. ${ }^{24}$ that demonstrated that some individuals with COPD did not have airflow limitation due to a rapid decline in lung function, but rather because of a slow decline in the setting of a low maximal $\mathrm{FEV}_{1}$ \% obtained in early adulthood $^{24}$. Further work is needed in this area to determine if those with COPD are more likely to have had a lower airway cross sectional area as young adults, and while it is unclear what clinical utility such a finding would have independent of spirometry, they are certainly intriguing as we seek to understand the origins of this disease.

\section{VASCULATURE}

The last anatomic compartment of the lung that is of interest in the imaging of COPD is the pulmonary vasculature. In the 1960s pulmonary angiography revealed pruning of the distal pulmonary vascular and associated dilation of the main pulmonary artery ${ }^{25,26}$. More recently, we have shown that this pruning is not only evident on much less invasive CT imaging, but is also associated with greater spirometric impairment and a lower six minute walk distance ${ }^{27}$. In addition, Wells et al. ${ }^{28}$ demonstrated that the proximal dilation of the main pulmonary artery measured on non-contrast CT images of the individuals with COPD is associated with AECOPD. This latter finding is of particular clinical interest as it does not require sophisticated image analysis tools or even contrast enhanced images. These characteristics make it easily implemented and widely available to the clinical community.

\section{NONPULMONARY}

One of the great benefits of chest CT imaging is that during image acquisition, images are obtained that include both the pulmonary and nonpulmonary components of the chest. While not always used to their fullest potential, the characteristics of the nonpulmonary components can reveal a great deal about a patient, particularly one with COPD. Perhaps one of the most insidious and dangerous systemic manifestations of COPD is the loss of skeletal muscle, which occurs in $25 \%$ of patients with COPD and is associated with a 50\% reduction in median survival ${ }^{29-31}$. Such cachexia largely results from the loss of fat free mass (FFM), but with aging there is a natural increase in adiposity, and therefore decreases in body mass index (BMI) are often a late finding and may not be helpful for the early detection this process, when it may be more amenable to 


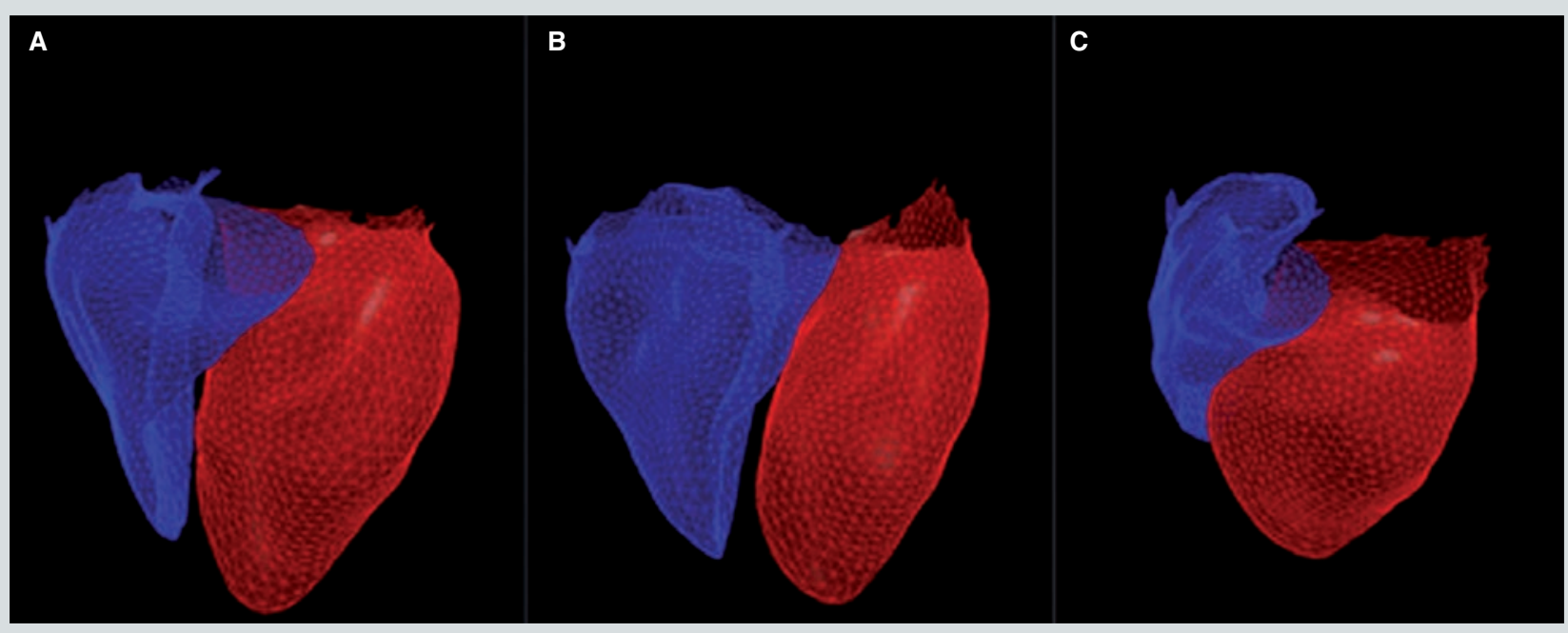

FIgURE 2. The right ventricle (RV, blue) and left ventricle (LV, red) in three subjects with a cardiac model fitted to the surface of the heart using volumetric non-contrast CT scan. A subject with GOLD 0 disease and with an RV/LV ratio of 0.5 , right ventricular systolic pressure (RVSP) of 20 and no evidence of ventricular dysfunction (A), a subject with GOLD 3 disease an RV/LV ratio of 0.8 , RV dilation, elevated RVSP of 47 (B), and a subject with GOLD 2 disease with LV dilation and ejection fraction of $35 \%$ (C) ${ }^{43}$.

therapeutic intervention ${ }^{32-36}$. CT imaging by contrast allows for the direct measurement of muscle bulk and fat free mass. For instance, MacDonald et al. ${ }^{37}$ demonstrated that pectoralis muscle bulk as measured on a single axial $\mathrm{CT}$ slice is inversely related to $\mathrm{FEV}_{1} \%$ and directly related to six minute was distance. Other nonpulmonary information that can be gleaned from the CTs of patients with COPD includes measures of bone mineral density for the detection of osteoporosis as well as coronary artery calcification, a measurement of cardiac disease ${ }^{38-40}$. Patients with COPD are at high risk for both of these diseases and the latter is the leading cause of death in patients with $\mathrm{COPD}^{41,42}$. More recently, we have shown that non-contrast CT imaging of the chest can even be used to accurately measure ventricular volume. More specifically, CT measures of right ventricular volume and curvature using a specific analysis technique are associated with similar measures obtained by cardiac magnetic resonance imaging (MRI) (Fig. 2) ${ }^{43}$. Given these advances it is reasonable to expect that someday all of the available raw data from a chest CT could be analyzed and used to assess various organ systems' structure and function.

\section{Interstitial lung disease}

\section{INTRODUCTION}

Over the past few decades imaging in respiratory diseases has been perhaps most useful in the diagnosis and characterization of interstitial lung diseases (ILD) such as idiopathic fibrosis (IPF). Visual analysis of high resolution CT imaging is especially important in diagnosis of IPF as in many cases its use obviates the need for lung biopsy ${ }^{44}$. But while 
CT imaging has proven useful in the initial diagnosis of IPF and other ILD, its role in the monitoring of disease progression is less clear. This is particularly important given the variability of other measures of disease severity such as forced vital capacity (FVC) and diffusing capacity for carbon monoxide $\left(\mathrm{DL}_{\mathrm{CO}}\right)$ and the recent introduction of the first viable treatment options for IPF ${ }^{45-48}$. Qualitative analysis of CT imaging has shown that there are a variety of visual markers of prognosis in IPF, including the presence of a usual interstitial pneumonia (UIP) pattern and disease severity as measured by visually derived scoring systems ${ }^{49-55}$. However, significant inter-observer variability exists in the visual characterization of those with ILD suggesting that there is a potential role for objective analysis as well ${ }^{56,57}$.

\section{ESTABLISHED DISEASE}

As with image analysis in COPD, much of the quantitative work in ILD has been using CT densitometry based approaches. For instance, higher values of mean lung density have been shown to be associated with worse pulmonary function as have specific measures of the density histogram for the entire lung such as lower skewness and kurtosis ${ }^{58-60}$. In addition, Best et al. $^{49}$ found that these latter measures, which represent how the tissue density in the lung is distributed, i.e. is there a greater percentage of lung occupied by higher density tissue than usual, are associated with mortality. Feature based approaches such as those using local histogram analysis described above in COPD have also been studied and used with some success in IPF and other interstitial lung diseases ${ }^{61-67}$. However the majority of this work has been in small cohorts in research settings and, in general, quantitative CT analysis in ILD has not found a clinical application yet. Moreover, quantitative imaging techniques often rely on the segmentation or separation of the lung from surrounding structures such as the chest wall. A variety of automated techniques have been developed to accomplish this task, but in general they are less accurate when there is a significant amount of high density tissue in the lung parenchyma ${ }^{68-70}$. That is to say, it is more difficult to automatically separate the lung from the chest wall when the two have similar densities, as is the case in many ILDs. This means that often laborious hand segmentation has to be used, which can be a very time consuming, and thus limiting, process. In addition, densitometry approaches in particular are often limited by the presence of high density fibrotic disease in combination with lower density emphysematous changes. Several small studies have attempted to perform densitometric analysis on patients with so-called combined pulmonary fibrosis and emphysema, but these have had conflicting and not always intuitive results ${ }^{71,72}$. Whether feature based approaches can overcome these limitations remains to be seen.

In addition to standard CT imaging, several studies utilizing combined positron emission tomography (PET) combined with CT have shown PET/CT to be a potentially useful tool in monitoring IPF disease activity. For instance, increased uptake of fluorodeoxyglucose ((18)F-FDG) on PET/CT is associated with impaired lung function in patients with IPF and other diffuse parenchymal lung diseases, and is correlated with disease severity in a bleomycin based mouse model of pulmonary fibrosis ${ }^{73,74}$. 


\section{EARLY DISEASE DETECTION}

Perhaps even more exciting from an image analysis standpoint, especially given the aforementioned challenges with the analysis of patients with advanced ILD, is the potential for automated techniques to identify early ILD, especially IPF. Over the past several years there has been a growing recognition that subtle, visually identified, radiologic patterns suggestive of fibrosis, often termed interstitial lung abnormalities (ILA), may be associated with a similar genetic association as IPF as well as lower lung volumes, an increased decline in lung function and increased mortality ${ }^{75-78}$. While these visual results are very compelling, the detection of these findings visually is time-consuming and requires highly trained experts limiting its utility at the population level. Objective approaches by contrast can potentially process large numbers of images on many patients very quickly. For instance, using a densitometric approach Lederer et al. $^{79}$ and Podolanczuk ${ }^{80-82}$ et al. have shown that the volume of lung that is occupied by dense or high attenuation tissue is directly associated with a variety of serum biomarkers known to be associated with lung disease, as well as with cigarette exposure, spirometric restriction and increased mortality. In addition, we have shown that an automated tool that utilizes local histogram and distance based analysis can detect visually defined ILA with reasonable accuracy (Fig. 3$)^{83}$. It is quite possible that someday such techniques might be used in combination with other biomarkers and genetic analysis to identify those patients at highest risk for IPF, potentially enabling early disease recognition and treatment, potentially preventing irreversible loss of lung function.
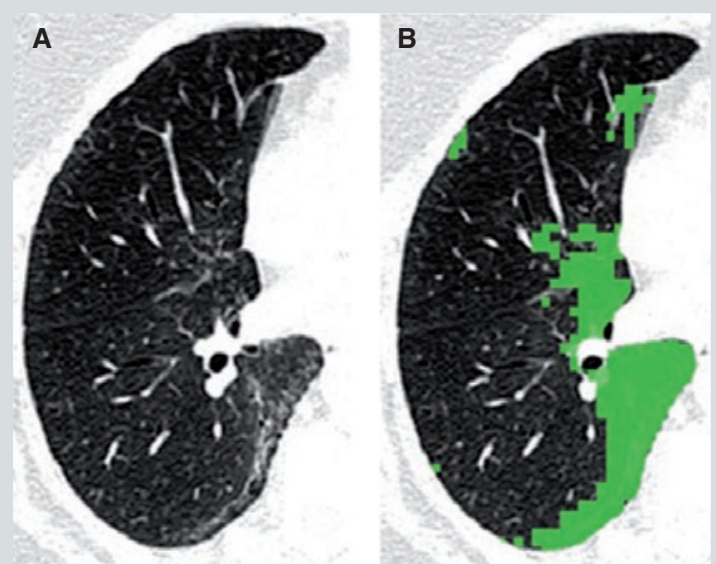

Figure 3. A: High resolution computed tomography (CT) image taken from a patient with interstitial lung abnormalities which may represent early pulmonary fibrosis. B: Overlay of label map (in green) utilizing a quantitative image analysis technique called local histogram analysis to detect and label all voxels with radiologic interstitial features on the same CT image ${ }^{83}$.

\section{Asthma}

\section{INTRODUCTION}

Of the chronic lung diseases, asthma is perhaps the least thought of as being characterized by imaging findings. To a large extent, with regard to visual analysis, this has been the case, especially with regard to standard chest radiography. While there are classically described chronic chest X-ray (CXR) findings in asthma, such as hyperinflation, these are not part of the diagnostic criteria, and, in general, chest radiography in asthma has been used to exclude other diseases or acute complications of asthma exacerbations such as pneumothoraces and pneumomediastinum ${ }^{84}$.

Similarly, much of the clinical use of CT imaging in asthma is centered on the exclusion of other associated conditions such as 
pneumothoraces in acute exacerbations, and the chronic presence of bronchiectasis. These do have some clinical utility. For instance, the presence of bronchiectasis or bronchial wall thickening has generally been associated with worse lung function and longer disease duration. That said, these associations have not been uniform across studies and it is not clear if they represent clinically meaningful differences in pathobiology or if they simply reflect disease progression ${ }^{84-94}$.

\section{COMPUTED TOMOGRAPHY}

Quantitative CT analysis in asthma has largely focused on two areas: the larger airways including the airway wall, and characterization of regional gas distribution in the parenchyma as a surrogate for small airway dysfunction. Similar to qualitative CT analysis, quantitative work by, for instance, Aysola et al. ${ }^{95}$, has shown that airway wall thickness percentage (the wall thickness divided by the outer airway diameter) is higher in those with severe asthma, and is inversely correlated to $\mathrm{FEV}_{1}$ \% (Fig. 4). Other groups have found similar relationships ${ }^{96}$. Although the resolution of current CT imaging techniques is not sufficient to visualize the small airways, the effect of small airways disease can be seen in the form of gas trapping. This can be measured either as a total amount across the entire lung, or, by using xenon enhanced CT, can be measured as regional variation ${ }^{4,84,85,97-103}$. Until recently, the latter approach was limited due to changes in lung volume between scans, but the development of dual energy xenon enhanced CT imaging has overcome that problem. For instance, using this technique, Chae et al. ${ }^{104}$ were able to calculate a ventilation defect score and found that it correlated with both the $\mathrm{FEV}_{1}$ to $\mathrm{FVC}$ ratio and the residual volume in stable asthmatics ${ }^{104}$. Using the same method, Kim et al. ${ }^{105}$ showed that this score was different between asthmatics and normal controls after a methacholine challenge. While such specialized imaging techniques are not yet ready for clinical application, they may provide new insights into the pathobiology of the disease. For instance, by combining density measures from inspiratory and expiratory CT images with a measure of airway tree complexity and the geometric airway measurements discussed above, Gupta et al. ${ }^{101}$ identified three novel asthma phenotypes, each with distinct radiographic and clinical features. As the push toward personalized medicine continues such work may ultimately help identify which patients should be included in specific clinical trials or who might benefit most from certain asthma therapies.

\section{MAGNETIC RESONANCE IMAGING}

The use of MRI in chest imaging generally is beyond the scope of this review. However, the role of MRI in asthma, at least in the research setting, is worth mention. With regard to MRI as a general chest imaging modality, the primary patient related limitations are the use of gas mixtures which, for the most part are anoxic, and the need for prolonged breath hold manoeuvres, sometimes up to 20 seconds $^{106,107}$. These combined can result in significant arterial oxygen desaturations during image acquisition, though typically not less than ninety percent, and the latter may not be feasible for many patients with lung disease. Work using oxygen enhanced MRI may help overcome the anoxic gas issue, but does not affect the breath 

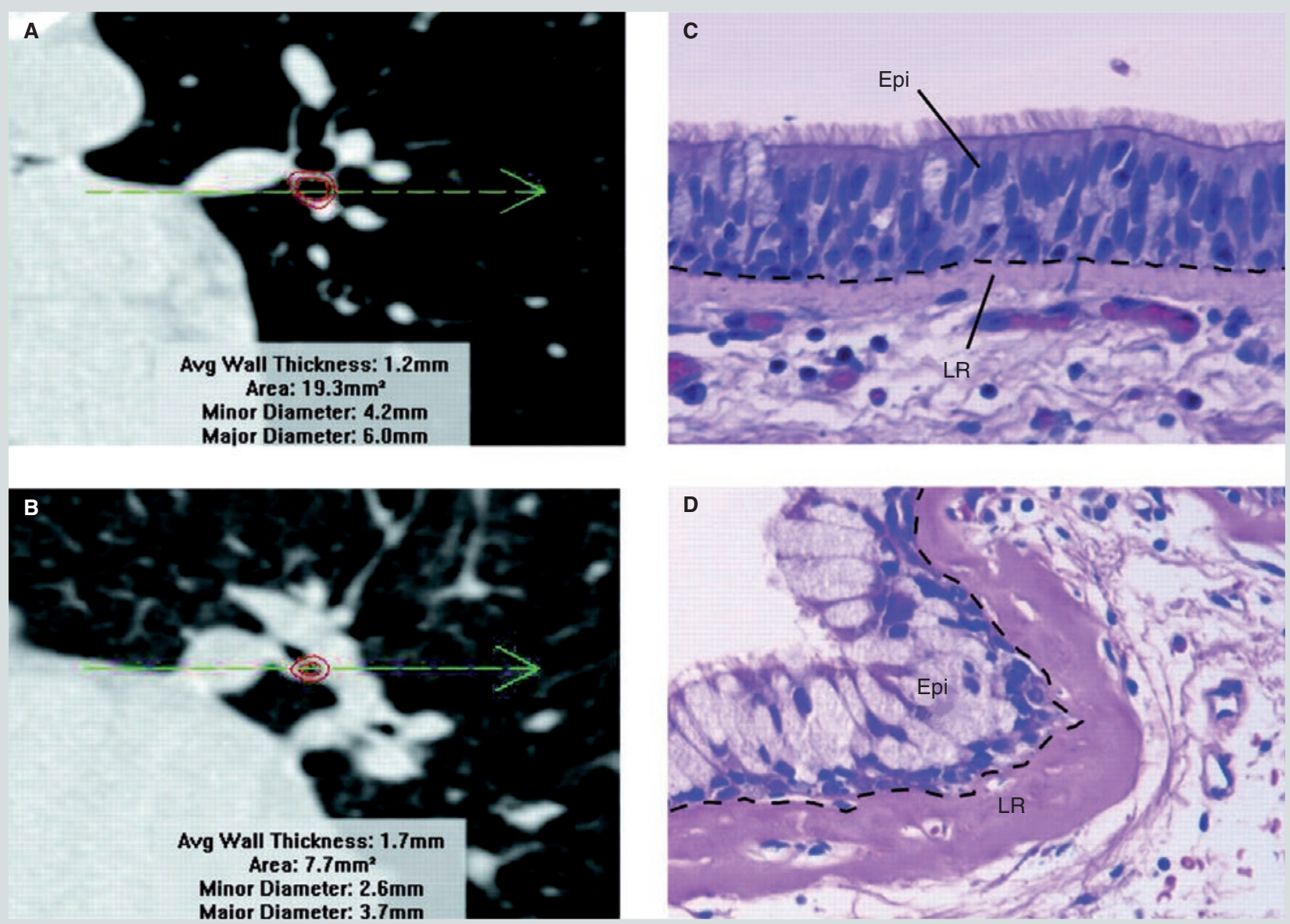

Figure 4. Computed tomography (CT) scan and hematoxylin-eosin stained bronchial biopsy images from a healthy normal patient (A and C) and patient with severe asthma (B and $\mathbf{D})$ demonstrating the increase in airway wall thickness in the patient with asthma which is evident both on CT and on the bronchial biopsy specimen. The latter demonstrates the thickening of the lamina reticularis in particular (reproduced with permission from Aysola $R S$ et al. ${ }^{95}$ ).

Epi: epithelium; LR: lamina reticularis.

hold duration ${ }^{10}$. In addition, the MRI images acquired using the aforementioned specialized gas mixtures that are required to measured regional variation in ventilation do not typically provide clear images of anatomic structures, though the use of co-registration with standard MRI or CT images may overcome this issue ${ }^{84,106,109-111}$. Despite these challenges, the ability of MRI to directly visualize regional variations in ventilation means it has the potential to help improve the understanding of certain aspects of asthma such as the co-existence of both intermittent and persistent ventilation defects in certain asthmatics (Fig. 5) $)^{112,113}$. It also may help guide and quantify response to therapy. For instance, in a small study, Thomen et al. ${ }^{114}$ found that bronchial thermoplasty results in a decrease in ventilation defect percentage in severe asthmatics. As with CT, further work is needed on MRI in asthma before it is ready for routine clinical use, but in the meantime it has the potential to significant insight into disease aetiology and response to therapy. 


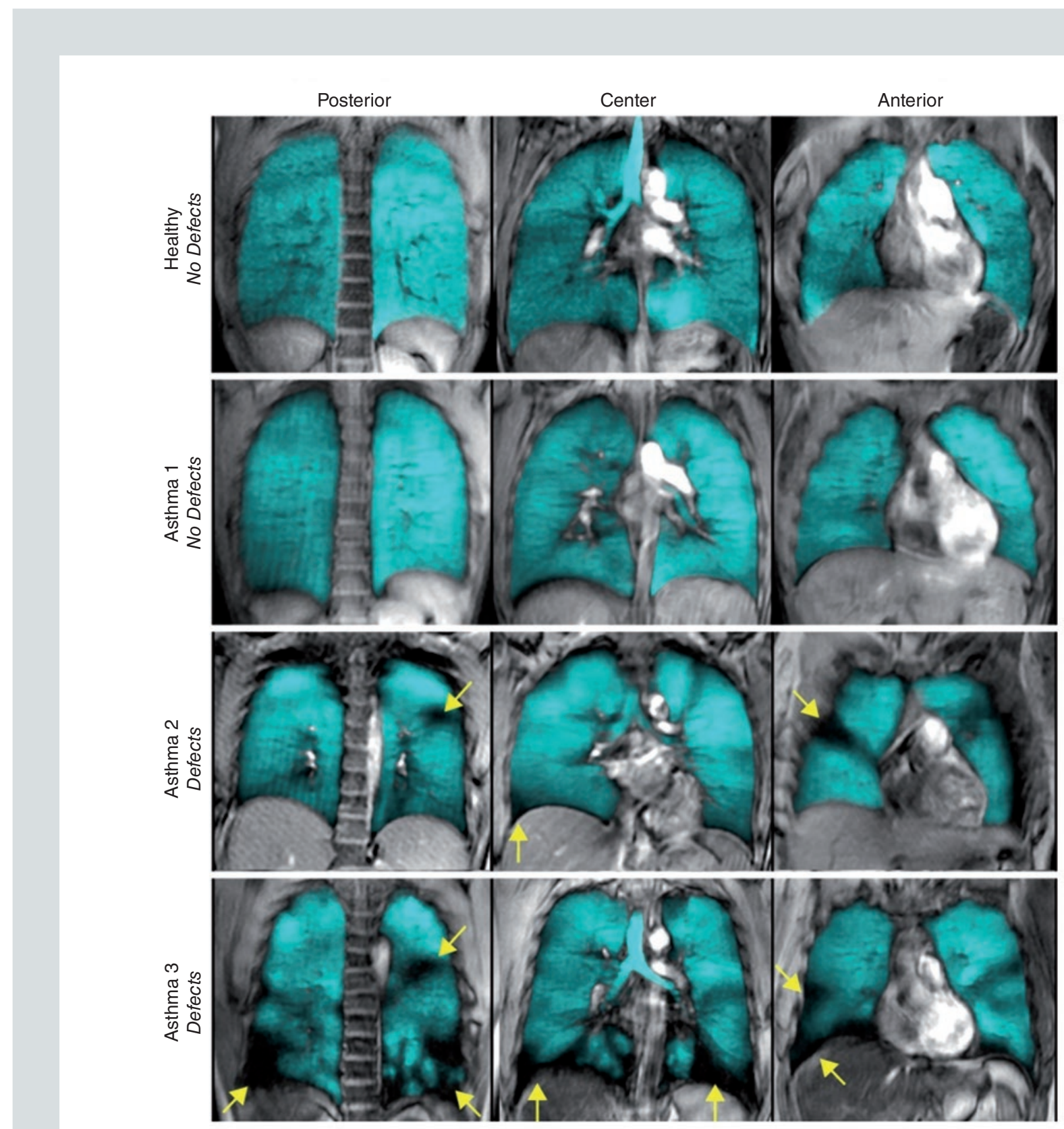

Figure 5. Hyperpolarized Magnetc Resonance Imaging (MRI) images from a healthy volunteer and three patients with asthma demonstrating the ability of MRI to detect ventilation defects. The healthy volunteer and asthma patient number 1 have no ventilation defects based on MRI. However, asthma patients 2 and 3 do have ventilation defects (highlighted with yellow arrows), as noted by the yellow arrows (reproduced with permission from Svenningsen $S$ et al. ${ }^{113}$ ).

\section{CONCLUSION}

The rapid growth of medical imaging and especially chest imaging, both in research and routine clinical care over the past several decades speaks to its importance in diagnosing and understanding both acute and chronic respiratory diseases. While the former are 
beyond the scope of this review, it is worth mentioning that chest radiography as well as $\mathrm{CT}$ and other modalities like ultrasound, have proven indispensable in diagnosing acute chest diseases, and there is vast amount of ongoing work examining new and exciting roles for techniques similar to those discussed above in conditions ranging from pulmonary embolism to pneumonia and pleural effusions. With regard to chronic respiratory diseases, $\mathrm{CT}$ in particular has greatly improved our understanding of diseases like COPD, ILD, and asthma, and quantitative $\mathrm{CT}$ imaging analysis may ultimately be a key component of our research into and treatment of these diseases. While the role of MRI in the imaging of these diseases is less well defined, it too has demonstrated its utility in the study of asthma in particular. In the past century we have come a long way from the use of Crookes tubes to obtain rudimentary radiographic images, but with the continued improvement in computer processing and image acquisition capabilities, it is possible that in the next hundred years we will see similar achievements in the area of medical imaging and chronic respiratory disease.

\section{RESEARCH FUNDING}

T32-HL007633 (Ash), R01-HL122464 (Washko), and R01-HL116473 (Washko).

\section{CONFLICT OF INTEREST}

Dr. Ash has nothing to disclose, Dr. Washko reports grants from Boehringer Ingelheim, other from Genentech, other from GlaxoSmithKline, other from PulmonX, from Janssen, during the conduct of the study; other from Quantitative Imaging Solutions, outside the submitted work.

\section{REFERENCES}

1. Morgan RH, Lewis I. The roentgen ray: its past and future. Dis Chest. 1945; 11:502-10.

2. Kerley P. Emphysema: (Section of Radiology). Proc R Soc Med. 1936;29: 1307-24.

3. Goddard PR, Nicholson EM, Laszlo G, Watt I. Computed tomography in pulmonary emphysema. Clin Radiol. 1982;33:379-87.

4. Muller NL, Staples CA, Miller RR, Abboud RT. "Density mask". An objective method to quantitate emphysema using computed tomography. Chest. 1988;94:782-7.

5. Hayhurst MD, MacNee W, Flenley DC et al. Diagnosis of pulmonary emphysema by computerised tomography. Lancet. 1984;2:320-2.

6. Coxson HO, Dirksen A, Edwards LD et al. The presence and progression of emphysema in COPD as determined by CT scanning and biomarker expression: a prospective analysis from the ECLIPSE study. Lancet Respir Med. 2013;1:129-36.

7. Kalender WA, Rienmuller R, Seissler W, Behr J, Welke M, Fichte H. Measurement of pulmonary parenchymal attenuation: use of spirometric gating with quantitative CT. Radiology. 1990;175:265-8.

8. Moroni C, Mascalchi M, Camiciottoli G et al. Comparison of spirometric-gated and -ungated HRCT in COPD. J Comput Assist Tomogr. 2003;27: 375-9.

9. Gierada DS, Yusen RD, Pilgram TK et al. Repeatability of quantitative CT indexes of emphysema in patients evaluated for lung volume reduction surgery. Radiology. 2001;220:448-54.

10. Santos J, Chaudhari AJ, Joshi AA et al. Non-rigid registration of serial dedicated breast CT, longitudinal dedicated breast CT and PET/CT images using the diffeomorphic demons method. Phys Med. 2014;30: 713-7.

11. Kauczor HU, Heussel CP, Fischer B, Hast J, Mildenberger P, Thelen M. [Value of spirometry-gated high resolution computerized tomography of the lung during inspiration and expiration]. Rofo. 1998;169:658-61.

12. Fishman A, Martinez F, Naunheim K et al. A randomized trial comparing lung-volume-reduction surgery with medical therapy for severe emphysema. N Engl J Med. 2003;348:2059-73.

13. Hersh CP, Washko GR, Jacobson FL et al. Interobserver variability in the determination of upper lobe-predominant emphysema. Chest. 2007;131: 424-31.

14. Cederlund K, Bergstrand L, Hogberg S, Rasmussen E, Svane B, Aspelin P. Visual grading of emphysema severity in candidates for lung volume reduction surgery. Comparison between HRCT, spiral CT and "density-masked" images. Acta Radiol. 2002;43:48-53.

15. Cederlund K, Bergstrand L, Hogberg S et al. Visual classification of emphysema heterogeneity compared with objective measurements: HRCT vs spiral CT in candidates for lung volume reduction surgery. Eur Radiol 2002;12:1045-51.

16. Cederlund K, Tylen U, Jorfeldt L, Aspelin P. Classification of emphysema in candidates for lung volume reduction surgery: a new objective and surgically oriented model for describing CT severity and heterogeneity. Chest. 2002;122:590-6.

17. Castaldi PJ, San Jose Estepar R, Mendoza CS et al. Distinct quantitative computed tomography emphysema patterns are associated with physiology and function in smokers. Am J Respir Crit Care Med. 2013;188: 1083-90. 
18. Patel IS, Vlahos I, Wilkinson TM et al. Bronchiectasis, exacerbation indices, and inflammation in chronic obstructive pulmonary disease. Am J Respir Crit Care Med. 2004;170:400-7.

19. Martinez-Garcia MA, de la Rosa Carrillo D, Soler-Cataluna JJ et al. Prognostic value of bronchiectasis in patients with moderate-to-severe chronic obstructive pulmonary disease. Am J Respir Crit Care Med. 2013;187: 823-31.

20. Nakano Y, Muro S, Sakai H et al. Computed tomographic measurements of airway dimensions and emphysema in smokers. Correlation with lung function. Am J Respir Crit Care Med. 2000;162:1102-8.

21. Reid L, Simon G. Pathological findings and radiological changes in chronic bronchitis and emphysema. Br J Radiol. 1959;32:291-305.

22. Fraser RG, Fraser RS, Renner JW, Bernard C, Fitzgerald PJ. The roentgenologic diagnosis of chronic bronchitis: a reassessment with emphasis on parahilar bronchi seen end-on. Radiology. 1976;120:1-9.

23. Washko GR, Diaz AA, Kim V, Barr RG et al. Computed tomographic measures of airway morphology in smokers and never-smoking normals. J Appl Physiol (1985). 2014;116:668-73.

24. Lange P, Celli B, Agusti A et al. Lung-Function Trajectories Leading to Chronic Obstructive Pulmonary Disease. N Engl J Med. 2015;373: 111-22.

25. Scarrow GD. The pulmonary angiogram in chronic bronchitis and emphysema. Proc R Soc Med. 1965;58:684-7.

26. Jacobson G, Turner AF, Balchum OJ, Jung R. Vascular changes in pulmonary emphysema. The radiologic evaluation by selective and peripheral pulmonary wedge angiography. Am J Roentgenol Radium Ther Nucl Med. 1967; 100:374-96.

27. Estepar RS, Kinney GL, Black-Shinn JL et al. Computed tomographic measures of pulmonary vascular morphology in smokers and their clinical implications. Am J Respir Crit Care Med. 2013;188:231-9.

28. Wells JM, Washko GR, Han MK et al. Pulmonary arterial enlargement and acute exacerbations of COPD. N Engl J Med. 2012;367:913-21.

29. Schols AM. Pulmonary cachexia. International journal of cardiology. 2002;85:101-10.

30. Wagner PD. Possible mechanisms underlying the development of cachexia in COPD. Eur Respir J. 2008;31:492-501.

31. Congleton J. The pulmonary cachexia syndrome: aspects of energy balance. Proc Nutr Soc. 1999;58:321-8.

32. Baumgartner RN, Stauber PM, McHugh D, Koehler KM, Garry PJ. Cross-sectional age differences in body composition in persons $60+$ years of age. J Gerontol A Biol Sci Med Sci. 1995;50:M307-16.

33. Kehayias JJ, Fiatarone MA, Zhuang H, Roubenoff R. Total body potassium and body fat: relevance to aging. Am J Clin Nutr. 1997;66:904-10.

34. Zamboni M, Armellini F, Harris T et al. Effects of age on body fat distribution and cardiovascular risk factors in women. Am J Clin Nutr. 1997;66: $111-5$.

35. Forbes GB. Longitudinal changes in adult fat-free mass: influence of body weight. Am J Clin Nutr. 1999;70:1025-31.

36. Newman AB, Lee JS, Visser $M$ et al. Weight change and the conservation of lean mass in old age: the Health, Aging and Body Composition Study. Am J Clin Nutr. 2005;82:872-8; quiz 915-6.

37. McDonald ML, Diaz AA, Ross JC et al. Quantitative computed tomography measures of pectoralis muscle area and disease severity in chronic obstructive pulmonary disease. A cross-sectional study. Annals of the American Thoracic Society. 2014;11:326-34

38. Budoff MJ, Hamirani YS, Gao YL et al. Measurement of thoracic bone mineral density with quantitative CT. Radiology. 2010;257:434-40.

39. Budoff MJ, Nasir K, Kinney GL et al. Coronary artery and thoracic calcium on noncontrast thoracic CT scans: comparison of ungated and gated examinations in patients from the COPD Gene cohort. Journal of cardiovascular computed tomography. 2011;5:113-8.

40. Williams MC, Murchison JT, Edwards LD et al. Coronary artery calcification is increased in patients with COPD and associated with increased morbidity and mortality. Thorax. 2014;69:718-23.
41. Lehouck A, Boonen S, Decramer M, Janssens W. COPD, bone metabolism, and osteoporosis. Chest. 2011;139:648-57.

42. Camilli AE, Robbins DR, Lebowitz MD. Death certificate reporting of confirmed airways obstructive disease. Am J Epidemiol. 1991;133:795-800.

43. Rahaghi FN, Sanchez-Ferrero GV, Minhas JK et al. Ventricular Geometry from Non-contrast Non-ECG Gated CT Scans: An Imaging Maker of Cardiopulmonary Disease in Smokers. Academic radiology. 2017.

44. Raghu G, Collard HR, Egan JJ et al. An official ATS/ERS/JRS/ALAT statement: idiopathic pulmonary fibrosis: evidence-based guidelines for diagnosis and management. Am J Respir Crit Care Med. 2011;183 788-824.

45. Lung function testing: selection of reference values and interpretative strategies. American Thoracic Society. Am Rev Respir Dis. 1991;144: 1202-18.

46. Azuma A, Nukiwa T, Tsuboi E et al. Double-blind, placebo-controlled tria of pirfenidone in patients with idiopathic pulmonary fibrosis. Am J Respir Crit Care Med. 2005;171:1040-7.

47. King TE, Jr., Bradford WZ, Castro-Bernardini S et al. A phase 3 trial of pirfenidone in patients with idiopathic pulmonary fibrosis. N Engl J Med. 2014;370:2083-92.

48. Richeldi L, du Bois RM, Raghu G et al. Efficacy and safety of nintedanib in idiopathic pulmonary fibrosis. N Engl J Med. 2014;370:2071-82.

49. Best AC, Meng J, Lynch AM et al. Idiopathic pulmonary fibrosis: physiologic tests, quantitative CT indexes, and CT visual scores as predictors of mortality. Radiology. 2008;246:935-40.

50. Lynch DA, Godwin JD, Safrin S et al. High-resolution computed tomography in idiopathic pulmonary fibrosis: diagnosis and prognosis. Am J Respir Crit Care Med. 2005;172:488-93.

51. Battista G, Zompatori M, Fasano L, Pacilli A, Basile B. Progressive worsening of idiopathic pulmonary fibrosis. High resolution computed tomog raphy (HRCT) study with functional correlations. Radiol Med. 2003;105: 2-11.

52. Shin KM, Lee KS, Chung MP et al. Prognostic determinants among clinical, thin-section CT, and histopathologic findings for fibrotic idiopathic interstitial pneumonias: tertiary hospital study. Radiology. 2008;249 328-37.

53. Sumikawa H, Johkoh T, Colby TV et al. Computed tomography finding in pathological usual interstitial pneumonia: relationship to survival. Am J Respir Crit Care Med. 2008;177:433-9.

54. Flaherty KR, Thwaite EL, Kazerooni EA et al. Radiological versus histological diagnosis in UIP and NSIP: survival implications. Thorax. 2003 58:143-8.

55. Wells AU, Desai SR, Rubens MB et al. Idiopathic pulmonary fibrosis: a composite physiologic index derived from disease extent observed by computed tomography. Am J Respir Crit Care Med. 2003;167:962-9.

56. Walsh SL, Calandriello L, Sverzellati N, Wells AU, Hansell DM, Consort UIPO. Interobserver agreement for the ATS/ERS/JRS/ALAT criteria for a UIP pattern on CT. Thorax. 2016;71:45-51.

57. Watadani T, Sakai F, Johkoh $\mathrm{T}$ et al. Interobserver variability in the $\mathrm{CT}$ assessment of honeycombing in the lungs. Radiology. 2013;266:936-44.

58. Hartley PG, Galvin JR, Hunninghake GW et al. High-resolution CT-derived measures of lung density are valid indexes of interstitial lung disease J Appl Physiol. 1994;76:271-7.

59. Best AC, Lynch AM, Bozic CM, Miller D, Grunwald GK, Lynch DA. Quantitative CT indexes in idiopathic pulmonary fibrosis: relationship with physiologic impairment. Radiology. 2003;228:407-14.

60. Rienmuller RK, Behr J, Kalender WA et al. Standardized quantitative high resolution CT in lung diseases. J Comput Assist Tomogr. 1991;15: 742-9.

61. Iwasawa T, Asakura A, Sakai F et al. Assessment of prognosis of patients with idiopathic pulmonary fibrosis by computer-aided analysis of CT images. J Thorac Imaging. 2009;24:216-22.

62. Iwasawa T, Ogura T, Sakai F et al. CT analysis of the effect of pirfenidone in patients with idiopathic pulmonary fibrosis. Eur J Radiol. 2014; 83: $32-8$. 
63. Xu Y, van Beek EJ, Hwanjo Y, Guo J, McLennan G, Hoffman EA. Computer-aided classification of interstitial lung diseases via MDCT: 3D adaptive multiple feature method (3D AMFM). Academic radiology. 2006;13: 969-78.

64. Jacob J, Bartholmai BJ, Rajagopalan S et al. Automated Quantitative Computed Tomography Versus Visual Computed Tomography Scoring in Idiopathic Pulmonary Fibrosis: Validation Against Pulmonary Function. J Thorac Imaging. 2016;31:304-11.

65. Jacob J, Bartholmai BJ, Rajagopalan S et al. Mortality prediction in IPF: evaluation of automated computer tomographic analysis with conventional severity measures. Eur Respir J. 2017;49(1).

66. Salisbury ML, Lynch DA, van Beek EJ et al. Idiopathic Pulmonary Fibrosis: Adaptive Multiple Features Method Fibrosis Association with Outcomes. Am J Respir Crit Care Med. 2016. [Epub ahead of print]

67. Bartholmai BJ, Raghunath S, Karwoski RA et al. Quantitative computed tomography imaging of interstitial lung diseases. J Thorac Imaging. 2013; 28:298-307.

68. Ross JC, Estepar RS, Diaz A et al. Lung extraction, lobe segmentation and hierarchical region assessment for quantitative analysis on high resolution computed tomography images. Medical image computing and computer-assisted intervention: MICCAI International Conference on Medical Image Computing and Computer-Assisted Intervention. 2009;12: 690-8.

69. Ross JC, Kindlmann GL, Okajima Y et al. Pulmonary lobe segmentation based on ridge surface sampling and shape model fitting. Med Phys. 2013; 40:121903.

70. Ross JC, San Jose Estepar R, Kindlmann G et al. Automatic lung lobe segmentation using particles, thin plate splines, and maximum a posteriori estimation. Medical image computing and computer-assisted intervention: MICCAI International Conference on Medical Image Computing and Computer-Assisted Intervention. 2010;13:163-71.

71. Ando K, Sekiya M, Tobino K, Takahashi K. Relationship between quantitative CT metrics and pulmonary function in combined pulmonary fibrosis and emphysema. Lung. 2013;191:585-91.

72. Matsuoka S, Yamashiro T, Matsushita S, Kotoku A, Fujikawa A, Yagihashi $\mathrm{K}$, et al. Quantitative CT evaluation in patients with combined pulmonary fibrosis and emphysema: correlation with pulmonary function. Academic radiology. 2015;22:626-31.

73. Bondue B, Sherer F, Van Simaeys G, Doumont G, Egrise D, Yakoub Y, et al. PET/CT with 18F-FDG- and 18F-FBEM-labeled leukocytes for metabolic activity and leukocyte recruitment monitoring in a mouse model of pulmonary fibrosis. J Nucl Med. 2015;56:127-32.

74. Groves AM, Win T, Screaton NJ, Berovic M, Endozo R, Booth H, et al. Idiopathic pulmonary fibrosis and diffuse parenchymal lung disease: implications from initial experience with 18F-FDG PET/CT. J Nucl Med. 2009; 50:538-45.

75. Araki T, Putman RK, Hatabu H, Gao W, Dupuis J, Latourelle JC, et al. Development and Progression of Interstitial Lung Abnormalities in the Framingham Heart Study. Am J Respir Crit Care Med. 2016.

76. Hunninghake GM, Hatabu H, Okajima Y, Gao W, Dupuis J, Latourelle JC, et al. MUC5B promoter polymorphism and interstitial lung abnormalities. N Engl J Med. 2013;368:2192-200.

77. Putman RK, Hatabu H, Araki T, Gudmundsson G, Gao W, Nishino M, et al. Association Between Interstitial Lung Abnormalities and All-Cause Mortality. Jama. 2016;315:672-81.

78. Washko GR, Hunninghake GM, Fernandez IE, Nishino M, Okajima Y, Yamashiro T, et al. Lung volumes and emphysema in smokers with interstitial lung abnormalities. N Engl J Med. 2011;364:897-906.

79. Lederer DJ, Enright PL, Kawut SM, Hoffman EA, Hunninghake G, van Beek EJ, et al. Cigarette smoking is associated with subclinical parenchymal lung disease: the Multi-Ethnic Study of Atherosclerosis (MESA)-lung study. Am J Respir Crit Care Med. 2009;180:407-14.

80. Podolanczuk A, Raghu G, Enright P, Peterson E, Johnson C, Barr RG, et al. Cross-Sectional Association Of Il-6 With Subclinical Interstitial Lung Dis- ease: The MESA Lung Fibrosis Study. Am J Respir Crit Care Med. 2015;191: A6067.

81. Podolanczuk A, Sonti R, Kawut SM, Raghu G, Enright P, Peterson E, et al Cross-Sectional Associations of Icam-1 And Hdl With Subclinical Interstitial Lung Disease: The MESA Lung Fibrosis Study. Am J Respir Crit Care Med. 2014;189:A3928.

82. Podolanczuk AJ, Oelsner EC, Barr RG, Hoffman EA, Armstrong HF, Austin $\mathrm{JH}$, et al. High attenuation areas on chest computed tomography in community-dwelling adults: the MESA study. Eur Respir J. 2016;48: 1442-52.

83. Ash SY, Harmouche R, Ross JC, Diaz AA, Hunninghake GM, Putman RK et al. The Objective Identification and Quantification of Interstitial Lung Abnormalities in Smokers. Academic radiology. 2016.

84. Ash SY, Diaz AA. The role of imaging in the assessment of severe asthma Current opinion in pulmonary medicine. 2017;23:97-102.

85. Walker C, Gupta S, Hartley R, Brightling CE. Computed tomography scans in severe asthma: utility and clinical implications. Current opinion in pulmonary medicine. 2012;18:42-7.

86. Walker C, Gupta S, Raj V, Siddiqui S, Brightling CE. Imaging advances in asthma. Expert Opin Med Diagn. 2011;5:453-65

87. Gupta S, Siddiqui S, Haldar P, Raj JV, Entwisle JJ, Wardlaw AJ, et al. Qualitative analysis of high-resolution CT scans in severe asthma. Chest. 2009; 136:1521-8.

88. Siddiqui S, Gupta S, Cruse G, Haldar P, Entwisle J, McDonald S, et al Airway wall geometry in asthma and nonasthmatic eosinophilic bronchitis. Allergy. 2009;64:951-8.

89. Paganin F, Seneterre E, Chanez P, Daures JP, Bruel JM, Michel FB, et al Computed tomography of the lungs in asthma: influence of disease severity and etiology. Am J Respir Crit Care Med. 1996;153:110-4.

90. Grenier P, Mourey-Gerosa I, Benali K, Brauner MW, Leung AN, Lenoir S, et al. Abnormalities of the airways and lung parenchyma in asthmatics: CT observations in 50 patients and inter- and intraobserver variability. Eur Radiol. 1996;6:199-206

91. Yilmaz S, Ekici A, Ekici M, Keles H. High-resolution computed tomography findings in elderly patients with asthma. Eur J Radiol. 2006;59: 238-43.

92. Takemura M, Niimi A, Minakuchi M et al. Bronchial dilatation in asthma: relation to clinical and sputum indices. Chest. 2004;125:1352-8.

93. Lynch DA, Newell JD, Tschomper BA, Cink TM, Newman LS, Bethel R Uncomplicated asthma in adults: comparison of CT appearance of the lungs in asthmatic and healthy subjects. Radiology. 1993;188:829-33.

94. Bumbacea D, Campbell D, Nguyen L et al. Parameters associated with persistent airflow obstruction in chronic severe asthma. Eur Respir J. 2004, 24:122-8.

95. Aysola RS, Hoffman EA, Gierada D, Wenzel S, Cook-Granroth J, Tarsi J, et al. Airway remodeling measured by multidetector CT is increased in severe asthma and correlates with pathology. Chest. 2008;134:1183-91.

96. Hartley RA, Barker BL, Newby C et al. Relationship between lung function and quantitative computed tomographic parameters of airway remodeling, air trapping, and emphysema in patients with asthma and chronic obstructive pulmonary disease: A single-center study. J Allergy Clin Immunol. 2016;137:1413-22 e12.

97. Guckel C, Wells AU, Taylor DA, Chabat F, Hansell DM. Mechanism of mosaic attenuation of the lungs on computed tomography in induced bronchospasm. J Appl Physiol (1985). 1999;86:701-8.

98. Busacker A, Newell JD, Jr., Keefe T et al. A multivariate analysis of risk factors for the air-trapping asthmatic phenotype as measured by quantitative CT analysis. Chest. 2009;135:48-56.

99. Gono H, Fujimoto K, Kawakami S, Kubo K. Evaluation of airway wall thickness and air trapping by HRCT in asymptomatic asthma. Eur Respir J. 2003;22:965-71.

100. Newman KB, Lynch DA, Newman LS, Ellegood D, Newell JD, Jr. Quantitative computed tomography detects air trapping due to asthma. Chest. 1994;106:105-9. 
101. Gupta S, Hartley R, Khan UT et al. Quantitative computed tomography-derived clusters: redefining airway remodeling in asthmatic patients. J Allergy Clin Immunol. 2014;133:729-38 e18.

102. Tunon-de-Lara JM, Laurent F, Giraud V et al. Air trapping in mild and moderate asthma: effect of inhaled corticosteroids. J Allergy Clin Immunol. 2007;119:583-90.

103. Gur D, Shabason L, Borovetz HS et al. Regional pulmonary ventilation measurements by xenon enhanced dynamic computed tomography: an update. J Comput Assist Tomogr. 1981;5:678-83.

104. Chae EJ, Seo JB, Goo HW et al. Xenon ventilation CT with a dual-energy technique of dual-source CT: initial experience. Radiology. 2008;248: 615-24.

105. Kim WW, Lee CH, Goo JM et al. Xenon-enhanced dual-energy CT of patients with asthma: dynamic ventilation changes after methacholine and salbutamol inhalation. AJR Am J Roentgenol. 2012;199:975-81.

106. Castro M, Fain SB, Hoffman EA et al. Lung imaging in asthmatic patients: the picture is clearer. J Allergy Clin Immunol. 2011;128:467-78.

107. Lutey BA, Lefrak SS, Woods JC et al. Hyperpolarized 3He MR imaging: physiologic monitoring observations and safety considerations in 100 consecutive subjects. Radiology. 2008;248:655-61.
108. Ohno Y, Nishio M, Koyama H et al. Asthma: comparison of dynamic oxygen-enhanced MR imaging and quantitative thin-section CT for evaluation of clinical treatment. Radiology. 2014;273:907-16.

109. Pennati F, Quirk JD, Yablonskiy DA, Castro M, Aliverti A, Woods JC. Assessment of regional lung function with multivolume $1 \mathrm{H}$ MR imaging in health and obstructive lung disease: comparison with $3 \mathrm{He}$ MR imaging. Radiology. 2014;273:580-90.

110. Tahir BA, Swift AJ, Marshall $\mathrm{H}$ et al. A method for quantitative analysis of regional lung ventilation using deformable image registration of $\mathrm{CT}$ and hybrid hyperpolarized gas/1H MRI. Phys Med Biol. 2014;59:7267-77.

111. Tahir BA, Van Holsbeke C, Ireland RH et al. Comparison of CT-based Lobar Ventilation with $3 \mathrm{He}$ MR Imaging Ventilation Measurements. Radiology 2016;278:585-92.

112. Svenningsen S, Guo F, Kirby M et al. Pulmonary functional magnetic resonance imaging: asthma temporal-spatial maps. Academic radiology. 2014; 21:1402-10.

113. Svenningsen S, Kirby M, Starr D et al. What are ventilation defects in asthma? Thorax. 2014;69:63-71.

114. Thomen RP, Sheshadri A, Quirk JD et al. Regional ventilation changes in severe asthma after bronchial thermoplasty with ${ }^{3} \mathrm{He}$ MR imaging and CT Radiology. 2015;274:250-9. 